\title{
The Psychology of Sustainability and Sustainable Development: Advancing Decent Work, Inclusivity, and Positive Strength-Based Primary Preventive Interventions for Vulnerable Workers
}

OPEN ACCESS

Edited by:

María del Carmen Pérez-Fuentes,

University of Almería, Spain

Reviewed by:

Paola Magnano,

Kore University of Enna, Italy

Ernesto Lodi,

University of Sassari, Italy

*Correspondence:

Andrea Svicher

andrea.svicher@unifi.it

tORCID:

Annamaria Di Fabio orcid.org/0000-0002-5150-1273

Andrea Svicher

orcid.org/0000-0001-5183-6113

Specialty section: This article was submitted to

Organizational Psychology, a section of the journal Frontiers in Psychology

Received: 31 May 2021 Accepted: 23 June 2021 Published: 27 July 2021

Citation:

Di Fabio A and Svicher A (2021) The Psychology of Sustainability and Sustainable Development: Advancing Decent Work, Inclusivity, and Positive Strength-Based Primary Preventive Interventions for Vulnerable Workers. Front. Psychol. 12:718354. doi: 10.3389/fpsyg.2021.718354

\section{Annamaria Di Fabio ${ }^{\dagger}$ and Andrea Svicher ${ }^{* \dagger}$}

Department of Education, Languages, Intercultures, Literatures and Psychology (Psychology Section), University of Florence, Florence, Italy

This study discusses the contribution of the psychology of sustainability and sustainable development to the wellbeing of vulnerable workers. The psychology of sustainability and sustainable development is a current area of the research study in the field of sustainability science. It deals with sustainability as a framework to recognize and integrate the value of the psychological approach in the construction of processes linked to sustainable development. Accordingly, the psychology of sustainability and sustainable development could provide sustainable development processes for the employment of vulnerable workers. The contribution starts with the definition of the coordinates of a sustainable development process for vulnerable workers, anchoring it to the principles of decent work and inclusivity. Subsequently, positive variables involved in the sustainable development processes and their relationship with decent work and inclusivity are discussed. Moreover, positive healthy organizations are introduced as work environments capable to take care of the wellbeing, also, of vulnerable workers. Lastly, the applications of positive strength-based primary preventive interventions for vulnerable workers are analyzed. Perspectives for further research studies and interventions are also examined.

Keywords: psychology of sustainability, sustainable development, decent work, inclusivity, vulnerable workers, healthy organizations, strength-based primary prevention perspective

\section{INTRODUCTION}

The 21 st century is undergoing rapid processes of changes characterized by acceleration (Rosa, 2013; Rosa et al., 2017), "liquid" multifaceted features (Bauman, 2013), and globalizations (Sparks et al., 2001). These continuous changes have had an impact on the labor market with a drastic reduction in the number and quality of available jobs (Johnson et al., 2018; Blustein et al., 2019a,b). Thereby, the wellbeing of workers is particularly at risk (Robertson and Cooper, 2010; Cartwright and Cooper, 2014; Di Fabio and Kenny, 2016). Recent systemic shocks (e.g., September 11/2001, attacks in the United States; 2007-2008 the global financial crisis) and the COVID-19 pandemic have exacerbated these trends (Blustein et al., 2020; Kniffin et al., 2021). Subjects at higher risk are those who were already vulnerable, marginalized, and discriminated against (Blustein et al., 2020; Tamin et al., 2021). 
They are ethnic minorities, women, sexual minorities, immigrants, disabled people, precarious workers, young people, and older people, which are called by scholars as vulnerable workers (Blustein et al., 2020; Tamin et al., 2021). The concept of vulnerable workers is very wide, including a very heterogeneous variety of situations and conditions. In detail, we use the Psychology of Working Framework (PWF) as a critical perspective that is able to deeply reflect between stable and peripheral workers (Guichard, 2009), recognizing peripheral workers in terms of the unemployed, underemployed, immigrants, the poor, and people with disabling conditions (Blustein et al., 2014). According to this concept, vulnerable workers tend to be disproportionately excluded (Burgess and Connell, 2015) or even pushed out of the workforce (Guichard, 2009) since systemic imbalances in power and privilege discourage them from career paths (Blustein et al., 2014). As a result, workers from the vulnerable groups experience a progressive reduction in resources, becoming locked into a vicious circle that pushes them to the margin of the labor market (Fang and Gunderson, 2015). Such an employment gap leads to a reduction in opportunities for vulnerable workers to the point that finding a job is highly unlikely or extremely difficult (e.g., Blustein et al., 2019c; Andreassen et al., 2020; Schuring et al., 2020). To face this context, Blustein and colleagues have called upon vocational psychologists to advance new research studies and interventions to address vulnerable workers toward greater social inclusion and decent work (Guichard, 2009; Peiró and Tetrick, 2011; Di Fabio and Blustein, 2016; Blustein et al., 2019a,b; Di Fabio and Kenny, 2019a; Duffy et al., 2020).

Opportunities may stem from the psychology of sustainability and sustainable development, a current framework for research study and intervention (Di Fabio, 2017a,b; Di Fabio and Rosen, 2018). The psychology of sustainability and sustainable development integrates the value of the psychological science enriching the transdisciplinary field of sustainability science that contributes directly to United Nations (UN) 17 Sustainable Development Goals (United Nations, 2021). It is focused on advancing new processes connected to sustainability and sustainable development to improve human wellbeing and quality of life considering different kinds of environments (i.e., from nature to individuals, communities, organizations, societies, ... until virtual environment and global environment) (Di Fabio and Rosen, 2018). The new keywords for managing developmental processes are promotion, enrichment, growth, and flexible change (Di Fabio and Rosen, 2018). This perspective analyzes sustainability via two axes of psychological reflection on what is sustainable for individuals, organizations, society, and the environment (Di Fabio, 2017a,b). The first axis (i.e., vertical) is related to the concept of time and involves dimensions of reflexivity that deals with understanding "where I come from," establishes awareness of "where I am," and proceeds to "where I will go" (Guichard, 2016; Di Fabio, 2017b). The second axis (i.e., horizontal) deals with the idea of space and others that are geographically near and far, and it is focused on dimensions of reflexivity that range from a self-centered position (i.e., egoistic) to a metacentric position (i.e., altruistic) (Maree, 2013; Di Fabio, $2017 b)$. The reflexivity process on this axis is focused on mutual gain exploring the balance between gain for others and gain for the self (Di Fabio, 2017b; Di Fabio and Tsuda, 2018).

Starting from these premises, coordinates for sustainable development process (Di Fabio, 2017b) in vulnerable workers could include on the vertical axis decent work (i.e., "where vulnerable workers are going" in terms of job development and professional planning) (Magnano et al., 2019, 2021; Zammitti et al., 2021) and on the horizontal axis inclusivity as a metacentric position to reduce the distance between vulnerable workers and the world of work. Moreover, sustainable development project for vulnerable workers has to consider optimal workplaces as able to protect the wellbeing of these individuals and to incorporate values in line with a sustainable development. According to this principle, advancing positive healthy organizations (Di Fabio, 2017a; Peiró, 2018) could be a promising solution. Positive healthy organizations are positive-oriented workplaces based on fostering resources, strengths, and talents of workers to achieve wellbeing (Di Fabio, 2017a,b; Johnson et al., 2018; SeguraCamacho et al., 2018; Peiró et al., 2020) including the new constructs of workplace relational civility (Di Fabio and Gori, 2016a) and sustainability of work-life projects (Di Fabio, 2017a; Di Fabio et al., 2018). Figure 1 illustrates the coordinates of our sustainable development project for vulnerable workers.

Thus, having in mind the idea of a sustainable development for vulnerable workers, which includes decent work and inclusivity as coordinates, this study aimed to discuss the following points: (a) examining positive psychological variables involved in sustainable development for vulnerable workers; (b) advancing the concept of positive healthy organization as workplaces capable to take care of the wellbeing of vulnerable workers; and (c) introducing the positive strength-based primary preventive perspective to foster wellbeing in vulnerable workers.

\section{POSITIVE PSYCHOLOGICAL VARIABLES FOR SUSTAINABLE DEVELOPMENT IN VULNERABLE WORKERS}

In this study, we examine the relationship between our coordinates for vulnerable workers (i.e., decent work and inclusivity) and positive variables involved in sustainable development. The positive variables are reflexivity, meaningfulness, connectedness, proximal zone, authentic self, the process of self-attunement, and harmonization (Di Fabio, 2017b; Di Fabio and Tsuda, 2018).

Concerning our purpose for a sustainable development project for vulnerable workers, decent work is the first coordinate on the vertical axis. This axis encompasses a process of psychological reflection investigating what is sustainable for vulnerable workers in their environments (from a macrolevel to a microlevel) (Di Fabio and Rosen, 2018). Decent work is defined by the psychology of working theory (PWT) as five job characteristics: (1) physically and psychologically safe working conditions, (2) adequate compensation, (3) sufficient rest/free time, (4) organizational values that incorporate family and social values, and (5) reasonable access to healthcare (Duffy et al., 2016). 


\section{World of Work}

\section{Psychology of Sustainability and Sustainable Development}

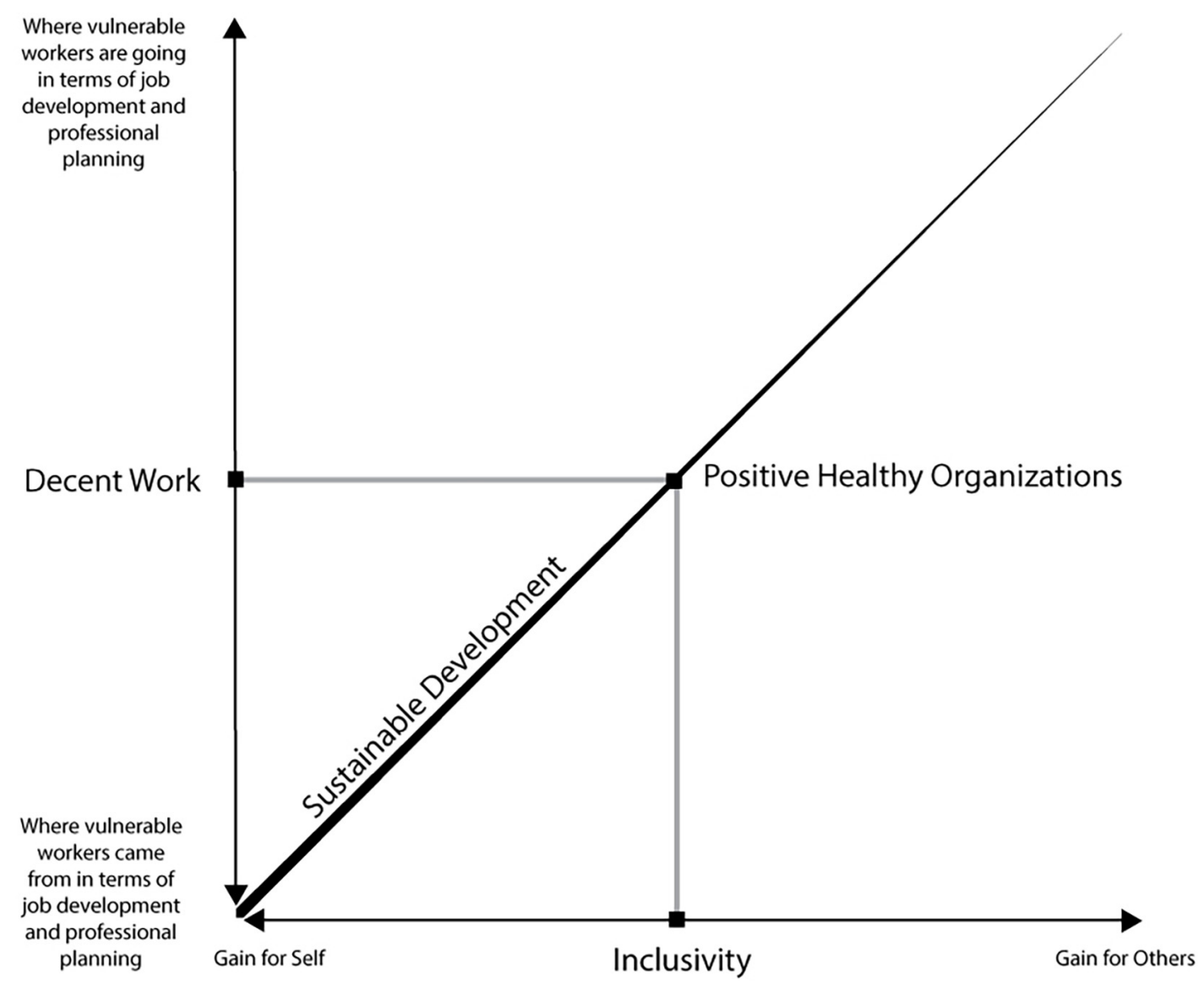

FIGURE 1 | Coordinates of the sustainable development project for vulnerable workers.

From a macrolevel perspective (i.e., society), decent work for vulnerable workers represents a sustainable developmental goal in line with the United Nations (2021) and the International Labor Organization (International Labour Organization, 2020). Decent work agenda (International Labour Organization, 2008) indicates four objectives for the sustainable development of decent work: (1) creating a sustainable institutional/economic milieu; (2) advancing/enhancing proposals of social/labor protection that are sustainable and adapted to national circumstances; (3) promoting social dialogue and tripartism (i.e., close connections between governments, worker organizations, and employers); and (4) respecting, promoting, and realizing the fundamental human rights at work (International Labour Organization, 2008; pp. 9-11).

From a microlevel perspective (i.e., individual), decent work is characterized by the achievement of three arrays of basic human needs that, in turn, enable wellbeing and work fulfillment (job satisfaction and work meaning): (1) survival and power (i.e., essential resources for survival and adaptive levels of control over the needed resources); (2) social connections/contributions, (i.e., the need to connect and contribute to a larger community); and (3) self-determination (i.e., the need for human behaviors to align with authentic and meaningful goals) (Duffy et al., 2016; Blustein, 2019).

The sustainability of providing vulnerable workers with the means for surviving and power is in accordance with the call of ILO for "an adequate minimum wage" (International Labour Organization, 2020) and international literature studies (Carr et al., 2018). In this context, the minimum wage is a tool to protect vulnerable workers from unduly low wages while also reducing inequality via balanced wage policies (International Labour Organization, 2020). The satisfaction of needs of social connection at work for vulnerable groups is in line with the concept of connectedness, one of the core 
principles of sustainability from a psychological perspective. Psychology of sustainability and sustainable development has developed connectedness to energize sustainable structures by better balancing relationships with community, society, and the natural world (Di Fabio and Tsuda, 2018). The sustainability of self-determination and meaning at work for vulnerable groups is in line with meaningfulness, another psychological core principle of sustainability that makes it possible to support the coherence, direction, significance, and belonging of the sustainable construction (Schnell et al., 2013; Di Fabio, 2017b). Moreover, the achievement of the three arrays of basic human needs could represent the starting point to activate personal resources and enable the shape from a motivational to a meaning paradigm, enhancing the involvement of individuals and increasing the chances of success (Di Fabio and Blustein, 2016; Di Fabio and Kenny, 2016; Di Fabio, 2017b).

The second coordinate of our sustainable development project for vulnerable workers includes inclusivity (Blustein et al., $2019 b)$ on the horizontal axis. Inclusivity is referred to all the efforts involved at various systemic levels for including individuals who have been marginalized by society (Blustein et al., 2019b). When inclusivity is under the light of sustainable development, it should be situated in the proximal zone of real progress (i.e., accounting for the real sustainability, not exceeding or investing less than available resources but always paying attention to peripheral workers with uncertain jobs and avoiding discrimination) (Guichard, 2009; Di Fabio, 2017b).

At the macrolevel (i.e., society), the proximal zone should be identified by national and international authorities, sustaining the efforts of vulnerable workers to access decent work both financially and with social recognition (Blustein et al., 2019a). At the microlevel (i.e., individual), the proximal zone for inclusivity should be assessed with the help of vocational psychologists applying sustainable career-management and self-management interventions for vulnerable workers (Blustein et al., 2019b).

To enhance inclusive psychological practice, PWT researchers have introduced the concept of agentic action (Blustein et al., $2019 b)$. Agentic action encompasses three clusters of possible sources that assess how individuals and systems can change (Blustein et al., 2019c). The first cluster is critical reflection and action, which refers to identify the systemic causes of injustice through the analysis of the overt and covert aspects of society (Blustein et al., 2019c). The second cluster is proactive engagement, reflecting the role of work volition, proactive personality, and career adaptability, which provides the psychological resources and direction for individuals to manage their life and work (Blustein et al., 2019c). The third cluster is social support and community engagement that captures relational support and social contribution (Kenny et al., 2018; Blustein et al., 2019c).

From the psychology of sustainability and sustainable development perspective (Di Fabio, 2017b; Di Fabio and Rosen, 2018), each source of agentic action for vulnerable workers could be expanded by practitioners through reflexivity, harmonization, the authentic self, and the process of self-attunement (Di Fabio and Tsuda, 2018). Reflexivity enhances moving into a new perspective to observe the transition problem, clarify priorities, and envision a possible future to concretely build on through action (Di Fabio, 2017b; Di Fabio and Tsuda, 2018). It also considers the deep value of harmonization in order to gain authentic aims through the concept of balance (Di Fabio, 2017b; Di Fabio and Tsuda, 2018). The authentic self and the process of self-attunement individuate objectives that are most vital for the individual and community in line with the attainment of a life of true meaning (Di Fabio and Tsuda, 2018).

As a whole, a sustainable development project for vulnerable workers requires opening a transdisciplinary reflection space (Di Fabio and Rosen, 2018) and involving and connecting communities, international organizations, and local governments. Furthermore, the vocational psychologist could apply sustainable career-management and self-management processes (Blustein et al., 2019b), gaining psychological strengths, personal resources, and growth of vulnerable workers supporting them through the developmental process indicated by our coordinates.

\section{ENRICHING THE POSITIVE PERSPECTIVE FOR MARGINALIZED AND VULNERABLE WORKERS: POSITIVE HEALTHY ORGANIZATIONS AND STRENGTH-BASED PRIMARY PREVENTION}

Achieving decent work is the pillar of our sustainable development project for vulnerable workers. Moreover, the sustainability of the organizational environment (Di Fabio, 2017b) is another fundamental aspect to preserve over time the wellbeing of vulnerable workers. A growing number of scholars have discussed the beneficial role of the passage from ill-health to positive health in organizations (i.e., focusing on the talents of employees and gifts to attain enhanced performance, satisfaction, and wellness) (e.g., Schaufeli, 2004; Tetrick and Peiró, 2012). Similarly, the last two decades have seen a significant increase in interest in positive psychological approaches (Seligman and Csikszentmihalyi, 2000; Seligman, 2002) to promote the wellbeing of employees and organizational resources (i.e., studying excellence and success rather than weakness, failure, and damage) (Di Fabio and Kenny, 2016; Di Fabio, 2017a,b; Puigmitja et al., 2019). Also, the psychology of sustainability and sustainable development pointed out the "positive sustainability" (Di Fabio, 2017a; Di Fabio and Peiró, 2018). This innovative aspect extended the concept of regenerating resources to the enhancement of wellbeing advancing the new processes of "rewellbeing, up-wellbeing, and crea(te)-wellbeing" (Di Fabio and Peiró, 2018). To this end, positive healthy organizations apply a positive primary prevention approach (Di Fabio, 2017b; Di Fabio et al., 2017; Di Fabio and Kenny, 2019b). Primary prevention is an early intervention that starts before the occurrence of problems (Caplan, 1964). It is centered on the building of the strengths of workers enhancing positive individual resources such as emotional intelligence (Di Fabio and Saklofske, 2014; Di Fabio, 2015), resilience (Di Fabio and Kenny, 2015; Wilson et al., 2017), 
and humor styles (Di Fabio and Duradoni, 2020). The focus on building resources and strengths (Di Fabio and Saklofske, 2021) in a primary preventive framework ( $\mathrm{Di}$ Fabio and Kenny, 2016; Di Fabio et al., 2017), namely positive strengthbased primary preventive, could be a promising approach for vulnerable workers.

An increasing number of studies have shown primary preventive approaches in the domain of sustainable sciences (e.g., Leporelli and Santi, 2019; Santi et al., 2019; Chotchoungchatchai et al., 2020; Nowacki et al., 2020), and scholars have advanced these interventions to foster the strengths of the employees (e.g., Di Fabio, 2019; Di Fabio and Duradoni, 2019, 2020). However, future studies are needed to expand knowledge on positive strength-based primary preventive interventions in vulnerable workers. As said, a reflection on the efficacy of these latter interventions in vulnerable workers deserves particular attention.

First, outside the concept of positive healthy organizations, positive strength-based primary preventive interventions could have limited efficacy. In fact, positive healthy organizations in a preventive perspective are centered on the enhancement of strengths at all organizational levels (i.e., the individual, the group, the organization, and the inter-organizational level) (Henry, 2005; Di Fabio, 2017a,b). Therefore, psychological resources are maintained through the right balance of a particular situation, sector, and culture, allowing endurance and sustainability of wellbeing (Di Fabio, 2017a,b; Di Fabio and Rosen, 2018). Such characteristics could be particularly optimal for vulnerable workers, which are in need of more complex interventions to be incentivized in the workplace (e.g., Srivastava and Chamberlain, 2005; Truxillo et al., 2012; Di Fabio and Gori, 2016a; Di Fabio and Duradoni, 2019).

Second, positive strength-based primary preventive interventions implemented without considering the sustainability of the work-life project (Di Fabio, 2017a,b) could have poor efficacy. Sustainability of the work-life project is fundamental in the employment of vulnerable workers (Stoilova et al., 2020; Opute et al., 2021) to find a balance between caregiving roles, family values, and working roles (Núñez et al., 2020; Rodríguez-Rivero et al., 2020). Conversely, the failure in work-life balance could have detrimental effects on the health of vulnerable workers (Blustein et al., 2019a,b). Positive healthy organizations link the sustainability of life-work projects to meaningful construction in employees via the positive psychological narratives of meaning (Di Fabio, 2014b; Di Fabio and Maree, 2016) that are a key part of the primary preventive approach. Positive psychological narratives of meaning are based on the intervention of Savickas "stored self" (Savickas, 2011) and help employees to build and foster optimal stories, beginning with specific real-life work circumstances (i.e., "from facts") and concluding with attention on relationships and details of meaning ("from perception of the facts" and "from success experience," respectively) (Blustein, 2011; Di Fabio and Blustein, 2016).

Third, positive strength-based primary preventive interventions on vulnerable workers that neglect the relational aspects of work could have a poor outcome, too. Relational aspects in the workplace are threatened for vulnerable workers, being at risk of various forms of discrimination, for example, racism (e.g., Storer et al., 2020; Rosander and Blomberg, 2021), sexism (e.g., Crewe and Wang, 2018; Velez et al., 2018), and exclusion (Cox, 2020; Friedman and Rizzolo, 2020). To prevent these phenomena, positive healthy organizations comprise workplace relational civility (i.e., relational decency, relational culture, and relational readiness) to strengthen positive interactions in organizational groups and reduce conflict in organizations (Di Fabio and Gori, 2016a).

Lastly, it is important to consider forms of leadership able to promote positive sustainability for vulnerable workers (Di Fabio and Peiró, 2018). The positive healthy organizational framework has recently developed the new construct of human capital sustainability leadership that integrates sustainability leadership (Di Fabio and Peiró, 2018) with ethical leadership (Yukl et al., 2013), mindful leadership (Herold, 2013), and servant leadership (Greenleaf, 1977). Sustainability leadership concerns the use of vigilant decision-making processes and sustainable development of human resources through continuous learning processes ( $\mathrm{Di}$ Fabio and Peiró, 2018). Ethical leadership encompasses fairness and aims to empower members of an organization (Yukl et al., 2013). Mindful leadership refers to paying attention to the present moment, recognizing and controlling personal cognition, and being aware of the own presence of an individual and the influence on other people (Herold, 2013). Servant leadership consists of sharing moral responsibility, allowing the growth of followers for their interests and needs and not only for the interests of the organizations (Greenleaf, 1977).

\section{CONCLUSION}

The psychology of sustainability and sustainable development (Di Fabio, 2017a,b; Di Fabio and Rosen, 2018) could be the framework for designing and constructing a sustainable project for long-lasting employment of vulnerable groups, which encompasses decent work and inclusivity as coordinates (Blustein et al., 2019a). Positive interventions from a microlevel to a macrolevel are available to ensure the sustainability of the project coordinates. The sustainability of decent work is enriched through metacentric reflexivity, connectedness, and meaningfulness (Di Fabio and Blustein, 2016; Duffy et al., 2016; Di Fabio, 2017a,b). Sustainability of inclusivity is fostered via reflexivity, harmonization, the authentic self, and the process of self-attunement (Di Fabio, 2014b, 2017a,b; Di Fabio and Tsuda, 2018). Positive healthy organizations (Di Fabio and Peiró, 2018; Di Fabio et al., 2020) are workplaces capable to take care of the wellbeing of vulnerable workers by applying positive strengthbased primary preventive interventions (Di Fabio and Kenny, 2016; Di Fabio and Saklofske, 2021) at all the organizational levels. For example, the construction of strengths at the individual level encompasses three types of interventions: intrapreneurial self-capital (Di Fabio, 2014a), acceptance of the change (Di Fabio and Gori, 2016b), and life project reflexivity (Di Fabio et al., 2018). Intrapreneurial self-capital intervention deals with the frequent career challenges by creating innovative solutions and turning the constraints of the environment into resources 
(Di Fabio, 2014a). Acceptance of change intervention referred to the tendency to embrace rather than shy away from changes since acceptance is viewed as positive for the wellbeing of an individual (Di Fabio and Gori, 2016b). Life projectuality intervention is aimed to stimulate the reflexivity of an individual regarding their future work-life projects by analyzing three areas: projectuality, authenticity, and acquiescence (Di Fabio et al., 2018). Furthermore, positive healthy organizations further protect and sustain endurance of wellbeing for vulnerable workers via the sustainability of work-life balance (Haar et al., 2014; Di Fabio, 2017a,b), workplace rational civility (Di Fabio and Gori, 2016a), and human capital sustainability leadership (Di Fabio and Peiró, 2018).

Concerning future research hypotheses, a recent study has provided new insights into the role of job crafting to shape decent work in vulnerable workers (Svicher and Di Fabio, 2021). Consequently, future research studies for vulnerable workers could also explore the links between job crafting, decent work, the psychology of sustainable development principles, and the healthy organization milieu. Another line of research study could investigate the relationship between decent work and occupational fatigue in vulnerable workers, studying the contribution of decent work in protecting vulnerable workers from occupational fatigue and the possible adjunctive improvement obtained by applying positive strength-based primary preventive interventions.

In brief, the psychology of sustainability and sustainable development represents an opportunity to create new research studies and intervention strategies to advance decent work as a human right (Duffy et al., 2017; Blustein et al., 2019c). This

\section{REFERENCES}

Andreassen, T. A., Breit, E., and Saltkjel, T. (2020). Research approaches to networked employment services: a systematic review. Soc. Policy Adm. 54, 1179-1197. doi: 10.1111/spol.12597

Bauman, Z. (2013). Liquid Modernity. Cambridge: Polity Press.

Blustein, D. L. (2011). A relational theory of working. J. Vocat. Behav. 79, 1-17. doi: 10.1016/j.jvb.2010.10.004

Blustein, D. L. (2019). The Importance of Work in an Age of Uncertainty: The Eroding Work Experience in America. New York, NY: Oxford University Press.

Blustein, D. L., Ali, S. R., and Flores, L. Y. (2019a). Vocational psychology: expanding the vision and enhancing the impact. Couns. Psychol. 47, 166-221. doi: 10.1177/0011000019861213

Blustein, D. L., DeVoy, J., Connors-Kellgren, A., and Olle, C. (2014). "Selfconstruction in an unstable world: Guichard's theory in the era of the great recession," in Century: Festschrift for Jean Guichard, eds A. Di Fabio and J. Bernaud (Hauppauge, NY: Nova Science Publishers), 75-86.

Blustein, D. L., Duffy, R., Ferreira, J. A., Cohen-Scali, V., Cinamon, R. G., and Allan, B. A. (2020). Unemployment in the time of COVID-19: a research agenda. J. Vocat. Behav. 119:103436. doi: 10.1016/j.jvb.2020.10 3436

Blustein, D. L., Kenny, M. E., Autin, K., and Duffy, R. (2019b). The psychology of working in practice: a theory of change for a new Era. Career Dev. Q. 67, 236-254. doi: 10.1002/cdq.12193

Blustein, D. L., Kenny, M. E., Di Fabio, A., and Guichard, J. (2019c). Expanding the impact of the psychology of working: engaging psychology in the struggle for decent work and human rights. J. Career Assess. 27, 3-28. doi: 10.1177/ 1069072718774002 challenging opportunity stems from the virtuous circle provided by linking together sustainability science, social justice policies (International Labour Organization, 2020; United Nations, 2021), positive psychological processes revitalizing strengths (e.g., Di Fabio, 2017a; Di Fabio and Saklofske, 2014, 2021; Di Fabio and Blustein, 2016; Di Fabio and Kenny, 2016), and positive healthy organizations protecting human dignity and equality (Di Fabio, 2017b; Di Fabio and Peiró, 2018).

\section{DATA AVAILABILITY STATEMENT}

The original contributions presented in the study are included in the article/supplementary material, further inquiries can be directed to the corresponding author.

\section{AUTHOR CONTRIBUTIONS}

AS wrote the first draft of the manuscript. ADF conceptualized the manuscript, supervised and tutored AS, reviewed, edited, and wrote the final draft of the manuscript. Both authors contributed to the article and approved the submitted version.

\section{FUNDING}

This research received no specific grant, but funding of the Department of Education, Languages, Intercultures, Literatures and Psychology (Psychology Section) at the University of Florence was used for publication fees.

Burgess, J., and Connell, J. (2015). Vulnerable work and strategies for inclusion: an introduction. Int. J. Manpower 36, 794-806. doi: 10.1108/IJM-06-2015-0085

Caplan, G. (1964). Principles of Preventive Psychiatry. Oxford: Basic Book.

Carr, S. C., Maleka, M., Meyer, I., Barry, M. L., Haar, J., Parker, J., et al. (2018). How can wages sustain a living? By getting ahead of the curve. Sustain. Sci. 13, 901-917.

Cartwright, S., and Cooper, C. L. (2014). "Towards organizational health: stress, positive organizational behavior, and employee well-being," in Bridging Occupational, Organizational and Public Health: A Transdisciplinary Approach, eds G. F. Bauer and O. Hämmig (New York, NY: Springer), 29-42. doi: 10.1007/ 978-94-007-5640-3_3

Chotchoungchatchai, S., Marshall, A. I., Witthayapipopsakul, W., Panichkriangkrai, W., Patcharanarumol, W., and Tangcharoensathien, V. (2020). Primary health care and sustainable development goals. Bull. World Health Organ. 98, 792-800. doi: 10.2471/blt.19.245613

Cox, C. (2020). Older adults and Covid 19: social justice, disparities, and social work practice. J. Gerontol. Soc. Work 63, 611-624. doi: 10.1080/01634372.2020. 1808141

Crewe, L., and Wang, A. (2018). Gender inequalities in the City of London advertising industry. Environ. Plan. 50, 671-688. doi: 10.1177/ 0308518X17749731

Di Fabio, A. (2014a). Intrapreneurial self-capital: a new construct for the 21st century. J. Employ. Couns. 51, 98-111. doi: 10.1002/j.2161-1920.2014.00045.x

Di Fabio, A. (2014b). "The new purposeful identitarian awareness for the twentyfirst century: valorize themselves in the Life Construction from youth to adulthood and late adulthood," in The Construction of the Identity in 21st Century: A Festschrift for Jean Guichard, eds A. Di Fabio and J.-L. Bernaud (New York, NY: Nova Science Publishers), 157-168. 
Di Fabio, A. (2015). Beyond fluid intelligence and personality traits in social support: the role of ability based emotional intelligence. Front. Psychol. 6:395. doi: 10.3389/fpsyg.2015.00395

Di Fabio, A. (2017a). Positive healthy organizations: promoting well-being, meaningfulness, and sustainability in organizations. Front. Psychol. 8:1938. doi: 10.3389/fpsyg.2017.01938

Di Fabio, A. (2017b). The psychology of sustainability and sustainable development for well-being in organizations. Front. Psychol. 8:1534. doi: 10.3389/fpsyg.2017. 01534

Di Fabio, A. (2019). "From career development to career management: a positive prevention perspective," in International Handbook of Career Guidance, eds J. A. Athanasou and H. N. Perera (New York, NY: Springer International Publishing), 209-240. doi: 10.1007/978-3-030-25153-6_10

Di Fabio, A., and Blustein, D. L. (2016). Editorial: from meaning of working to meaningful lives: the challenges of expanding decent work. Front. Psychol. 7:1119. doi: 10.3389/fpsyg.2016.01119

Di Fabio, A., and Duradoni, M. (2019). Fighting incivility in the workplace for women and for all workers: the challenge of primary prevention. Front. Psychol. 10:1805. doi: 10.3389/fpsyg.2019.01805

Di Fabio, A., and Duradoni, M. (2020). Humor styles as new resources in a primary preventive perspective: reducing resistance to change for negotiation. Int. J. Environ. Res. Public Health 7:2485. doi: 10.3390/ijerph17072485

Di Fabio, A., and Gori, A. (2016a). Assessing workplace relational civility (WRC) with a new multidimensional "Mirror" Measure. Front. Psychol. 7:890. doi: 10.3389/fpsyg.2016.00890

Di Fabio, A., and Gori, A. (2016b). Developing a new instrument for assessing acceptance of change. Front. Psychol. 7:802. doi: 10.3389/fpsyg.2016.00802

Di Fabio, A., and Kenny, M. E. (2015). The contributions of emotional intelligence and social support for adaptive career progress among Italian youth. J. Career Dev. 42, 48-59. doi: 10.1177/0894845314533420

Di Fabio, A., and Kenny, M. E. (2016). From decent work to decent lives: positive self and relational management (PS\&RM) in the twenty-first century. Front. Psychol. 7:361. doi: 10.3389/fpsyg.2016.00361

Di Fabio, A., and Kenny, M. E. (2019a). Decent work in Italy: context, conceptualization, and assessment. J. Vocat. Behav. 110, 131-143. doi: 10.1016/ j.jvb.2018.10.014

Di Fabio, A., and Kenny, M. E. (2019b). Resources for enhancing employee and organizational well-being beyond personality traits: the promise of Emotional Intelligence and Positive Relational Management. Pers. Individ. Differ. 151:109278. doi: 10.1016/j.paid.2019.02.022

Di Fabio, A., and Maree, J. G. (2016). A psychological perspective on the future of work: promoting sustainable projects and meaning-making through grounded reflexivity. Couns. G. Ital. Ric. Appl. 9:3.

Di Fabio, A., and Peiró, J. M. (2018). Human capital sustainability leadership to promote sustainable development and healthy organizations: a new scale. Sustainability 10:2413. doi: 10.3390/su10072413

Di Fabio, A., and Rosen, M. A. (2018). Opening the black box of psychological processes in the science of sustainable development: a new frontier. Eur. J. Sustain. Dev. Res. 2:47. doi: 10.20897/ejosdr/3933

Di Fabio, A., and Saklofske, D. H. (2014). Promoting individual resources: the challenge of trait emotional intelligence. Pers. Individ. Differ. 65, 19-23. doi: 10.1016/j.paid.2014.01.026

Di Fabio, A., and Saklofske, D. H. (2021). The relationship of compassion and self-compassion with personality and emotional intelligence. PAID 40th Anniversary Special Issue. Pers. Individ. Differ. 169:110109. doi: 10.1016/j.paid. 2020.110109

Di Fabio, A., and Tsuda, A. (2018). The psychology of harmony and harmonization: advancing the perspectives for the psychology of sustainability and sustainable development. Sustainability 10:4726. doi: 10.3390/su1012 4726

Di Fabio, A., Cheung, F., and Peiró, J.-M. (2020). Editorial special issue personality and individual differences and healthy organizations. Pers. Individ. Differ. 166:110196. doi: 10.1016/j.paid.2020.110196

Di Fabio, A., Kenny, M. E., and Claudius, M. (2017). "Preventing distress and promoting psychological well-being in uncertain times through career management intervention," in The Cambridge Handbook of International Prevention Science, eds M. Israelashvili and J. L. Romano (Cambridge: Cambridge University Press), 233-254.
Di Fabio, A., Maree, J. G., and Kenny, M. E. (2018). Development of the Life Project Reflexivity Scale: a new career intervention inventory. J. Career Assess. 27, 358-370. doi: 10.1177/1069072718758065

Duffy, R. D., Allan, B. A., England, J. W., Blustein, D. L., Autin, K. L., Douglass, R. P., et al. (2017). The development and initial validation of the Decent Work Scale. J. Couns. Psychol. 63, 206-221. doi: 10.1037/cou0000191

Duffy, R. D., Blustein, D. L., Allan, B. A., Diemer, M. A., and Cinamon, R. G. (2020). Introduction to the special issue: a cross-cultural exploration of decent work. J. Vocat. Behav. 116:103351. doi: 10.1016/j.jvb.2019.103351

Duffy, R. D., Blustein, D. L., Diemer, M. A., and Autin, K. L. (2016). The psychology of working theory. J. Couns. Psychol. 63, 127-148. doi: 10.1037/cou0000140

Fang, T., and Gunderson, M. (2015). Vulnerable groups in Canada and labour market exclusion. Int. J. Manpow. 36, 824-847. doi: 10.1108/IJM-02-2014-0052

Friedman, C., and Rizzolo, M. C. (2020). Fair-Wages for people with disabilities: barriers and facilitators. J. Disabil. Policy Stud. 31, 152-163. doi: 10.1177/ 1044207320919492

Greenleaf, R. K. (1977). Servant Leadership. Mahwah, NJ: Paulist Press.

Guichard, J. (2009). Self-constructing. J. Vocat. Behav. 75, 251-258. doi: 10.1016/j. jvb.2009.03.004

Guichard, J. (2016). Reflexivity in life design interventions: comments on life and career design dialogues. J. Vocat. Behav. 97, 78-83. doi: 10.1016/j.jvb.2016. 08.001

Haar, J. M., Russo, M., Suñe, A., and Ollier-Malaterre, A. (2014). Outcomes of work-life balance on job satisfaction, life satisfaction and mental health: a study across seven cultures. J. Vocat. Behav. 85, 361-373. doi: 10.1016/j.jvb.2014. 08.010

Henry, J. (2005). “The healthy organization," in Research Companion to Organizational Health Psychology, eds A. S. G. Antoniou and C. L. Cooper (Cheltenham: Edward Elgar), 382-391.

Herold, I. M. H. (2013). The mindful library leader. Libr. Issues Brief. Fac. Adm. $33,1-4$.

International Labour Organization (2008). ILO Declaration on Social Justice for a Fair Globalization. Available online at: https://www.ilo.org/wcmsp5/groups/ public/---dgreports/---cabinet/documents/genericdocument/wcms_371208. pdf (accesed May 21, 2021).

International Labour Organization (2020). Global Wage Report 2020-21: Wages and Minimum Wages in the Time of COVID-19. Geneva: International Labour Office. Available online at: https:/www.ilo.org/wcmsp5/groups/public/--dgreports/---dcomm/---publ/documents/publication/wcms_762534.pdf (accesed May 21, 2021).

Johnson, S., Robertson, I., and Cooper, C. L. (2018). Wellbeing: Productivity and Happiness at Work, 2nd Edn. London: Palgrave Macmillan.

Kenny, M. E., Blustein, D. L., and Meerkins, T. M. (2018). Integrating relational perspectives in career counseling practice. Career Dev. Q. 66, 135-148. doi: $10.1002 /$ cdq. 12128

Kniffin, K. M., Narayanan, J., Anseel, F., Antonakis, J., Ashford, S. P., Bakker, A. B., et al. (2021). COVID-19 and the workplace: implications, issues, and insights for future research and action. Am. Psychol. 76, 63-77. doi: 10.1037/ amp0000716

Leporelli, E., and Santi, G. (2019). From psychology of sustainability to sustainability of urban spaces: promoting a primary prevention approach for well-being in the healthy city designing. a waterfront case study in Livorno. Sustainability 11:760. doi: 10.3390/su11030760

Magnano, P., Santisi, G., Zammitti, A., Zarbo, R., and Di Nuovo, S. (2019). SelfPerceived employability and meaningful work: the mediating role of courage on quality of life. Sustainability 11:764.

Magnano, P., Zammitti, A., and Santisi, G. (2021). Representations of work and decent work and life planning. Qualitative research on a group of socially vulnerable people. TMP 28, 99-111. doi: 10.4473/TPM28.1.7

Maree, J. G. (2013). Couselling for career construction: Connecting life themes to construct life portraits. Turning pain into hope. Rotterdam: Sense.

Nowacki, J., Mekel, O., Martin-Olmedo, P., and Cave, B. (2020). Opportunities for achieving the sustainable development goals through assessing health in environmental assessments. Eur. J. Public Health 30:5. doi: 10.1093/eurpub/ ckaa165.1375

Núñez, R. B., Bandeira, P., and Santero-Sánchez, R. (2020). Social economy, gender equality at work and the 2030 agenda: theory and evidence from Spain. Sustainability 12:12. doi: 10.3390/su12125192 
Opute, J., Hack-Polay, D., and Rigby, M. (2021). "The employment situation of migrant workers and their experience of work-life pressures," in Migration Practice as Creative Practice, eds D. Hack-Polay, A. B. Mahmoud, A. Rydzik, M. Rahman, P. A. Igwe, and G. Bosworth (Bingley: Emerald Publishing Limited), 83-99. doi: 10.1108/978-1-83867-765-720211011

Peiró, J. M. (2018). "Stress and coping at work: new research trends and their implications for practice," in The Individual in the Changing Working Life, eds K. Näswall, J. Hellgren, and M. Sverke (Cambridge: Cambridge University Press), 284-310.

Peiró, J. M., and Tetrick, L. (2011). “Occupational health psychology” in IAAP Handbook of Applied Psychology, eds J. C. Quick and L. E. Tetrick (London: Routledge), 292-315. doi: 10.1002/9781444395150.ch12

Peiró, J. M., Bayonab, J. A., Caballer, A., and Di Fabio, A. (2020). Importance of work characteristics affects job performance: the mediating role of individual dispositions on the work design-performance relationships. PAID 40th Anniversary Special Issue. Pers. Individ. Differ. 157:109808. doi: 10.1016/j. paid.2019.109808

Puigmitja, I., Robledo, E., and Topa, G. (2019). Cross-cultural validity and psychometric properties of the ISC Intrapreneurial Self-Capital Scale in Spain. Pers. Individ. Differ. 151:109296. doi: 10.1016/j.paid.2019.02.040

Robertson, I., and Cooper, C. L. (2010). Wellbeing: Productivity and Happiness at Work. London: Palgrave Macmillan.

Rodríguez-Rivero, R., Yáñez, S., Fernández-Aller, C., and Carrasco-Gallego, R. (2020). Is it time for a revolution in work-life balance? reflections from Spain. Sustainability 12:22. doi: 10.3390/su12229563

Rosa, H. (2013). Social Acceleration. A New Theory of Modernity. New York, NY: Columbia University Press.

Rosa, H., Dörre, K., and Lessenich, S. (2017). Appropriation, activation and acceleration: the escalatory logics of capitalist modernity and the crises of dynamic stabilization. Theory Cult. Soc. 34, 53-73. doi: 10.1177/ 0263276416657600

Rosander, M., and Blomberg, S. (2021). Workplace bullying of immigrants working in Sweden. Int. J. Hum. Resource Manag. doi: 10.1080/09585192.2021.1891113 [Epub ahead of print].

Santi, G., Leporelli, E., and Di Sivo, M. (2019). Improving sustainability in architectural research: biopsychosocial requirements in the design of Urban spaces. Sustainability 11:1585.

Savickas, M. L. (2011). Career Counseling. Washington, DC: American Psychological Association.

Schaufeli, W. B. (2004). The future of occupational health psychology. Appl. Psychol. 53, 502-517. doi: 10.1111/j.1464-0597.2004.00184.x

Schnell, T., Höge, T., and Pollet, E. (2013). Predicting meaning in work: theory, data, implications. J. Posit. Psychol. 8, 543-554.

Schuring, M., Robroek, S. J. W., Carrino, L., O’Prinsen, A. C., Oude Hengel, K. M., Avendano, M., et al. (2020). Does reduced employment protection increase the employment disadvantage of workers with low education and poorer health? J. Epidemiol. Community Health 74, 851-857. doi: 10.1136/jech-2020-21 3772

Segura-Camacho, A., García-Orozco, J. J., and Topa, G. (2018). Sustainable and healthy organizations promote employee well-being: the moderating role of selection, optimization, and compensation strategies. Sustainability 10:3411. doi: 10.3390/su10103411

Seligman, M. E. P. (2002). "Positive psychology, positive prevention, and positive therapy," in Handbook of Positive Psychology, eds C. R. Snyder and S. J. Lopez (Oxford: Oxford University Press), 3-9.

Seligman, M. E. P., and Csikszentmihalyi, M. (2000). Positive psychology: an introduction. Am. Psychol. 55, 5-14. doi: 10.1037/0003-066X.55.1.5

Sparks, K., Faragher, B., and Cooper, C. L. (2001). Well-being and occupational health in the 21st century workplace. J. Occup. Organ. Psychol. 74, 489-509. doi: 10.1348/096317901167497
Srivastava, S., and Chamberlain, A. (2005). Factors determining job retention and return to work for disabled employees: a questionnaire study of opinions of disabled people's organizations in the UK. J. Rehabil. Med. 37, 17-22. doi: $10.1080 / 16501970410033839$

Stoilova, R., Ilieva-Trichkova, P., and Bieri, F. (2020). Work-life balance in Europe: institutional contexts and individual factors. Int. J. Sociol. Soc. Policy 40, 366-381. doi: 10.1108/IJSSP-08-2019-0152

Storer, A., Schneider, D., and Harknett, K. (2020). What explains racial/ethnic inequality in job quality in the service sector? Am. Sociol. Rev. 85, 537-572. doi: $10.1177 / 0003122420930018$

Svicher, A., and Di Fabio, A. (2021). Job crafting: a challenge to promote decent work for vulnerable workers. Front. Psychol. 12:1827. doi: 10.3389/fpsyg.2021. 681022

Tamin, J., Samuel, O., Suraya, A., Ebuenyi, I. D., Naicker, N., and Rajput-Ray, M. (2021). Vulnerable workers and COVID-19: insights from a survey of members of the international commission for occupational health. Int. J. Environ. Res. Public Health 18:346.

Tetrick, L. E., and Peiró, J. M. (2012). “Occupational safety and health," in The Oxford Handbook of Organizational Psychology, Vol. 2, ed. S. W. J. Kozlowski (New York, NY: Oxford University Press), 1228-1244. doi: 10.1093/oxfordhb/ 9780199928286.013.0036

Truxillo, D. M., Cadiz, D. M., Rineer, J. R., Zaniboni, S., and Fraccaroli, F. (2012). A lifespan perspective on job design: fitting the job and the worker to promote job satisfaction, engagement, and performance. Organ. Psychol. Rev. 2, 340-360. doi: $10.1177 / 2041386612454043$

United Nations (2021). Transforming Our World: the 2030 Agenda for Sustainable Development. New York, NY: United Nations. Availabe online at: https://sdgs. un.org/2030agenda (accessed May 20, 2021).

Velez, B. L., Cox, R. Jr., Polihronakis, C. J., and Moradi, B. (2018). Discrimination, work outcomes, and mental health among women of color: the protective role of womanist attitudes. J. Couns. Psychol. 65, 178-193. doi: 10.1037/cou0000274

Wilson, C. A., Plouffe, R. A., Saklofske, D. H., Di Fabio, A., Prince-Embury, S., and Babcock, S. E. (2017). Resiliency across cultures: a validation of the resiliency scale for young adults. J. Psychoeduc. Assess. 37, 14-25. doi: 10.1177/ 0734282917740017

Yukl, G., Mahsud, R., Hassan, S., and Prussia, G. E. (2013). An improved measure of ethical leadership. J. Leadersh. Organ. Stud. 20, 38-48. doi: 10.1177/ 1548051811429352

Zammitti, A., Magnano, P., and Santisi, G. (2021). The concepts of work and decent work in relationship with self-efficacy and career adaptability: research with quantitative and qualitative methods in adolescence. Front. Psychol. 12:660721. doi: 10.3389/fpsyg.2021.660721

Conflict of Interest: The authors declare that the research was conducted in the absence of any commercial or financial relationships that could be construed as a potential conflict of interest.

Publisher's Note: All claims expressed in this article are solely those of the authors and do not necessarily represent those of their affiliated organizations, or those of the publisher, the editors and the reviewers. Any product that may be evaluated in this article, or claim that may be made by its manufacturer, is not guaranteed or endorsed by the publisher.

Copyright (C) 2021 Di Fabio and Svicher. This is an open-access article distributed under the terms of the Creative Commons Attribution License (CC BY). The use, distribution or reproduction in other forums is permitted, provided the original author(s) and the copyright owner(s) are credited and that the original publication in this journal is cited, in accordance with accepted academic practice. No use, distribution or reproduction is permitted which does not comply with these terms. 